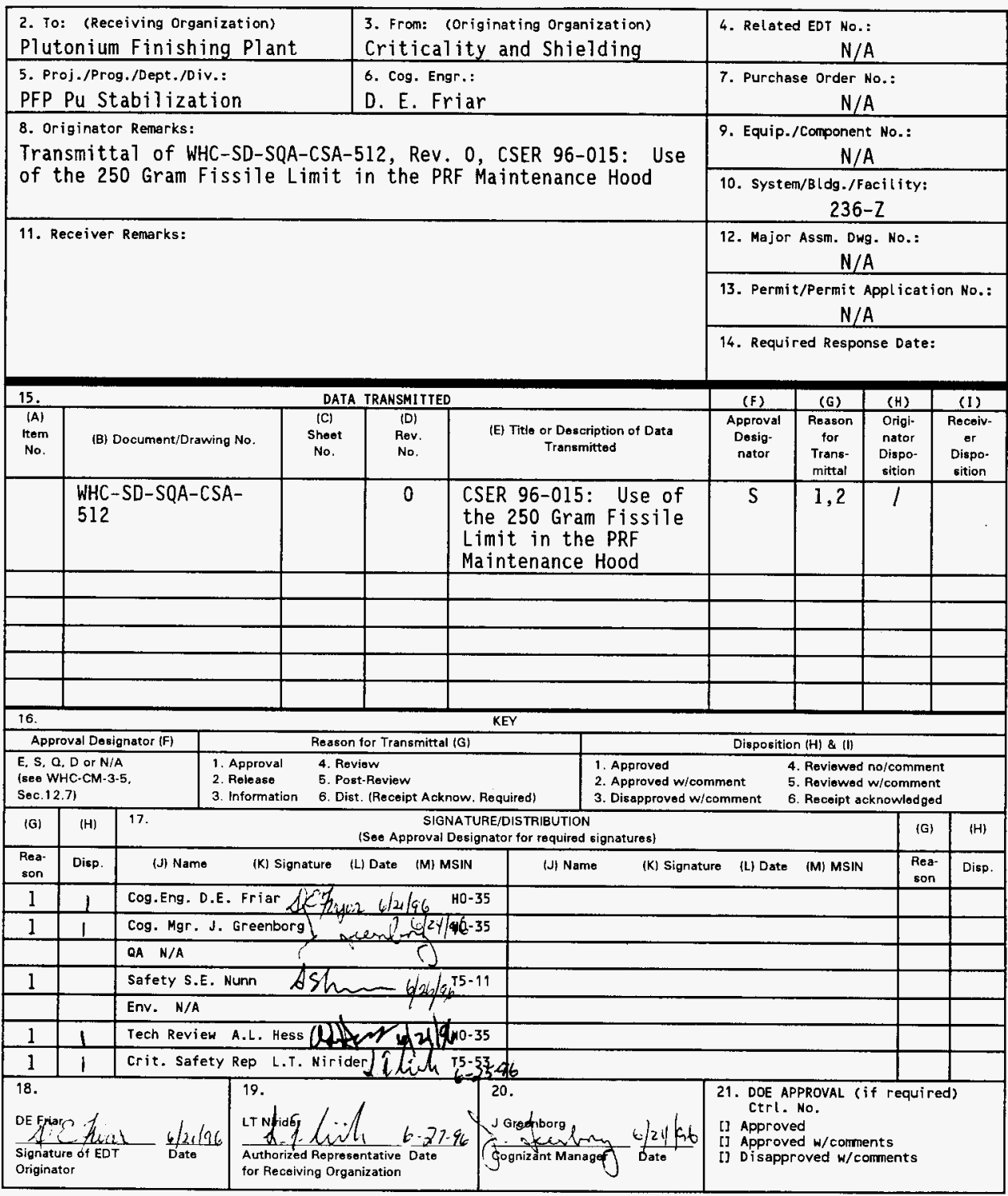

BD -7400-172-2(04/94) GEF097 


\section{CSER 96-015: Use of the 250 Gram Fissile Limit in the PRF Maintenance Hood}

\section{E. Friar}

Westinghouse Hanford Company, Richland, WA 99352

U.S. Department of Energy Contract DE-AC06-87RL10930

$\begin{array}{lll}\text { EDT/ECN: } & 616556 & \text { UC: } 507 \\ \text { Org Code: } & 8 M 730 & \text { Charge Code: } \\ \text { B\&R Code: } & \text { EW700303000 } & \text { Total Pages: } 7\end{array}$

Key Words: PRF, 236-Z, Maintenance Hood, CSER

Abstract: This criticality safety evaluation allows the application of a 250 gram fissile limit to the operation of the maintenance glovebox in 236-Z at the Plutonium Finishing Plant.

TRADEMARK DISCLAIMER. Reference herein to any specific commercial product, process, or service by trade name, trademark, manufacturer, or otherwise, does not necessarily constitute or imply its endorsement, recomendation, or favoring by the United States Government or any agency thereof or its contractors or subcontractors.

Printed in the United States of America. To obtain copies of this document, contact: WHC/BCS Document Control Services, P.O. Box 1970, Mailstop H6-08, Richland WA 99352, Phone (509) 372-2420; Fax (509) 376-4989.

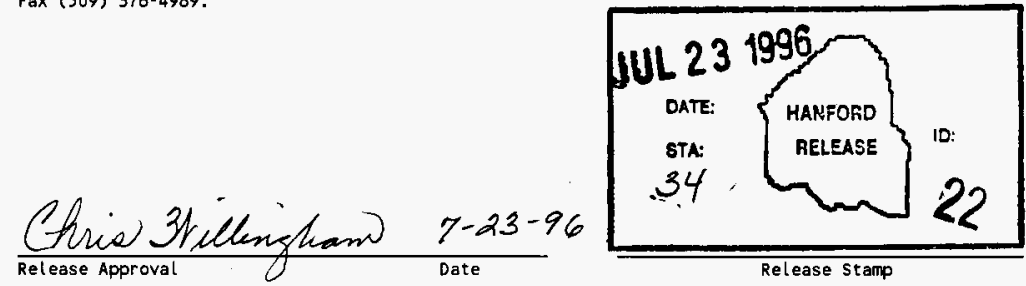


WHC-SD-SQA-CSA-512, Rev. 0

Page 1

Tit7e: CSER 96-015: USE OF THE 250 GRAM FISSILE LIMIT IN THE PRF MAINTENANCE HOOD

Prepared by: As deval

D. E. Friar, Principal Engineer

Criticality Evaluation Team

Date: $2 / 2 / 96$

\author{
Criticality Evaluation Tean
}

Reviewed by: $\frac{C 246}{\text { A. L. Hess, Principal Engineer Date: } 6 / 2 r / 96}$ Criticality Evaluation Team

Approved by:

The Plutonium Finishing Plant (PFP) operating organization requests that the 250 gram fissile limit set from the Uniform. Laboratory Specification be applied to the maintenance hood in the Plutonium Reclamation Facility (PRF). This evaluation documents that the requested 1 imit set, currently set $D$ in WHC 1996, may be applied to the maintenance hood in room 27 of the PRF. If this limit set is used, the general requirements and general limits of the Uniform Laboratory Specifications also apply to the maintenance hood.

The request to establish the new limit set is shown in Figure 1 . In the request, operations supplies the following information about the maintenance hood:

- Current work is cementing sludge scrapings in $1 / 2$ iiter polyjars

- The fissile content of a polyjar is about 5 grams

- Sludge scrapings are produced in batches of from 5 to about 40 potyjars

- Operations may use the maintenance hood for maintenance work, from time to time

o The maintenance hood contains no external water sources. 
WHC-SD-SQA-CSA-512, Rev. 0

Page 2

The PRF portion of the PFP facility, including room 27 and the maintenance hood, is illustrated in the attached sketch (Figure 2). The maintenance hood is not adjacent to any other glovebox or fissile array. The PRF access bay gloveboxes on the second floor of PRF are about 15 feet from the maintenance hood.

The proposed limit set, originally established in Layman 1979, is as follows (paraphrased):

1. The $\mathrm{H} / \mathrm{Pu}$ ratio is unrestricted

2. The minimum ${ }^{240} \mathrm{Pu}$ content in the plutonium (for amounts of $\mathrm{Pu}$ in excess of 15 grams) is 3 percent

3. The maximum number of unit masses is 1

4. The maximum total mass of piutonium and ${ }^{235} \mathrm{U}$ is 250 grams

5. The fissile form is not restricted

6. The maximum volume of a single container is 10.0 liters

7. The number of containers is not limited

8. The minimum edge-to-edge spacing between the unit mass and other fissile material, including behind non-isolating walls, is 10 inches $(25 \mathrm{~cm})$

9. The quantity of liquid permitted in containers is not limited

10. The fire fighting category is " $\mathrm{C}$ ".

This limit set conforms to the double contingency principle as described in Layman 1979. Briefly, a full double batch of 500 grams is less than the generally accepted plutonium minimum critical mass of 520 grams. In fact, over a kilogram of plutonium is required for criticality in a 10 liter sphere having full water reflection and containing a Pu-water mixture with $3 \% 240 \mathrm{Pu}$ (see Figure 3, from Carter, et al, 1968, III.A.9(97)-4). The spacing limit helps prevent overbatching and restricts interaction with any nearby fissile materiat.

There are no unusual accumulations of fissile material, reflectors, or quantities of special moderator present.

Operations may change to another applicable limit set for the maintenance hood by following the requirements stated in the Uniform Laboratory Specification, including verification of compliance, documentation, notifications, training, and replacing the postings.

Operations is reminded to include glovebox holdup values in the inventory, also in accordance with the general specification. 
WHC-SD-SQA-CSA-512, Rev, 0

Page 3

\section{References}

Carter, R. D., G. R. Kiel, and K. R. Ridgway, 1968, Criticality Handbook, ARH-600, Rockwell Hanford Operations, RichTand, Washington.

Layman, B. J., 1979, CSER 79-014: Uniform Specification; 250 Grams, WHC-SDSQA-CSA-20175, Rockwell Hanford Operations, Richland, Washington.

WHC, 1996, Uniform Laboratory Specifications, Rev. C-4, CPS-L-114-00020, Westinghouse Hanford Company, Richland, Washington.

\section{Reviewer Comments}

A. L. Hess of the Criticality Evaluation Team in the Criticality and Shielding Section carried out the technical review of this evaluation, for which the following comments were provided.

The referenced material and data were reviewed, and the adequacy of the criticality safety margin with the imposed limits is confirmed. Some clarification may be useful regarding the expression "unit mass". In the context of this particular Limit Set, the unit mass encompasses all of the fissile-material bearing containers in the glovebox, no matter how they may be spread out, and the $250 \mathrm{~g}$ limit applies to the total fissile in this accumulation. The 10-inch spacing then refers to the boundary of this container collection relative to any significant fissile amount outside of the glovebox. 
WHC-SD-SQA-CSA-512, Rev. 0 Page 4

\section{Figure 1: Request for Evaluation}

It would be extremely advantageous from a safety and operations standpoint to have a new set of approved limits for cxiticality safety in the PRF Maintenance Hood located in Room \#27 of the 236-z Building.

This hood was designated as a maintenance hood during PRF operational days and had a specific limit set assigned to it for that purpose. The hood is now only occasionally used for mainenance purposes. The most recent activity being performed in that location is cementing of $1 / 2$ liter polyjars containing sludge scrapings from the PRF access bay gloveboxes. These items are produced in quantities ranging from 5 to about 30 or 40 at a time. The typical polyjar in this operation contains approximately 5 grams of plutonium.

I am suggesting that we approve the 250 gram LIMIT SET D as described in CPS-I-114-00020 for this purpose. I would like to getain the maintenance limits described in CPS-Z-165-80727 for use when maintenance activities are performed in the bood. We will control the limits by the normal glovebox posting process in place here at PFP.

Hood \#27 contains no external water sources, is not adjacent to any other glovebox or array with the exception of the PRF access bay gloveboxes on the 2nd floor of PRF which are approximately 5 meters distant. Room $\$ 27$ is a totally enclosed and separate room which. contains only the glovebox and some equipment storage shelves. I believe that approval of this limit for this work will remove a serious tulnerability in terms of compliance with restrictive criticality safety limits which presently exists. Basically, low-level plutonium work is being performed in a hood with an unnecessarily restrictive set of limits.

Would you prepare a CSER which approves the Maintenance Hood in Room $\$ 27$ for the above mentioned Iimit set? Let me know how I can help. operations would like to have this approved in 2 - or 3 -weeks if possible.

\section{THANKS ! !}

\section{Tom}


WHC-SD-SQA-CSA-512, Rev. 0

Page 5

Figure 2: Building 236-Z floor Plans
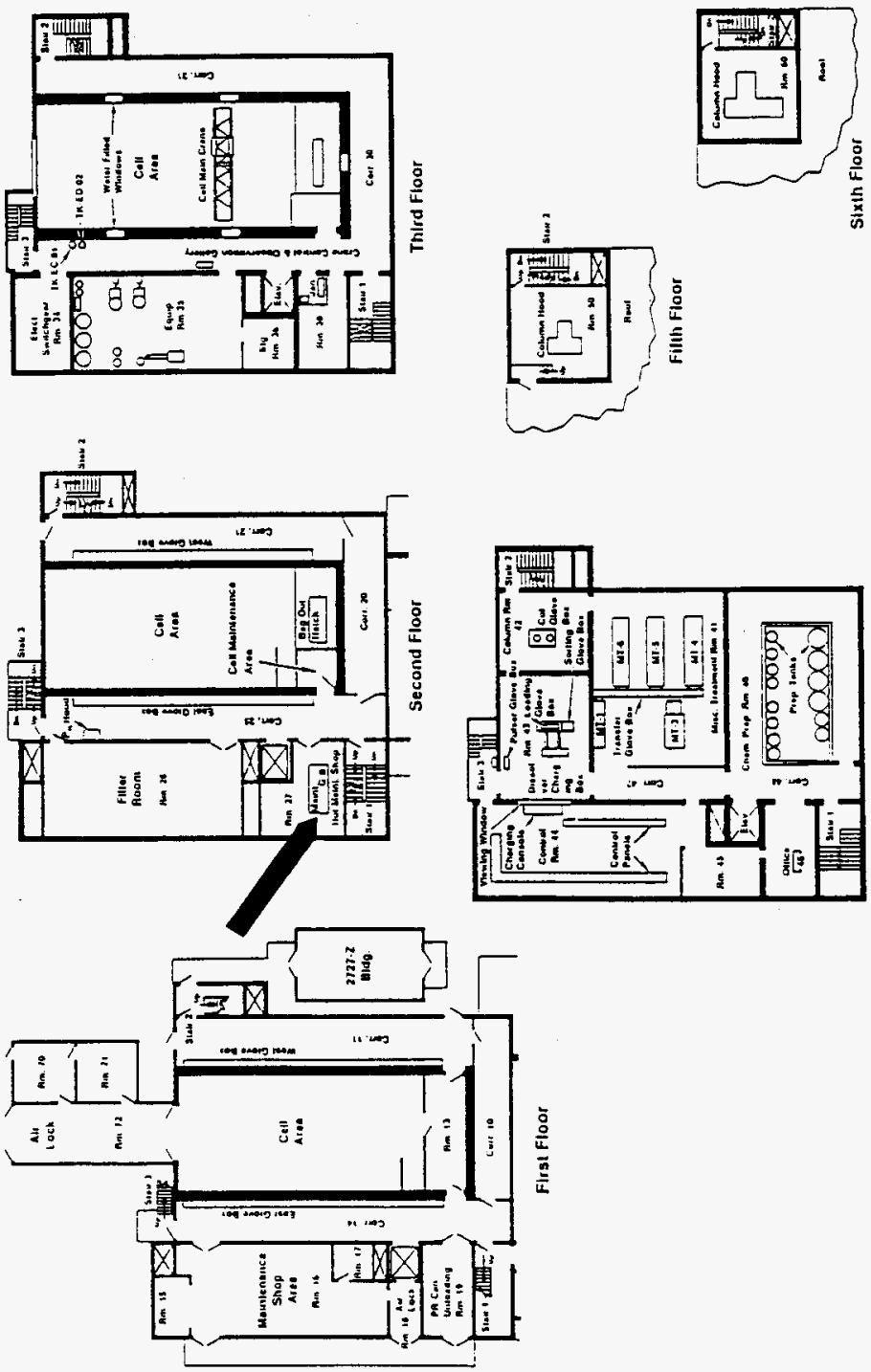
WHC-SD-SQA-CSA-512, Rev. 0

Page 6

\section{Figure 3: Critical Sphere Volume vs. Critical Spherical Mass Plutonium- $\mathrm{H}_{2} \mathrm{O}-3 \mathrm{Wt} \% 240$}

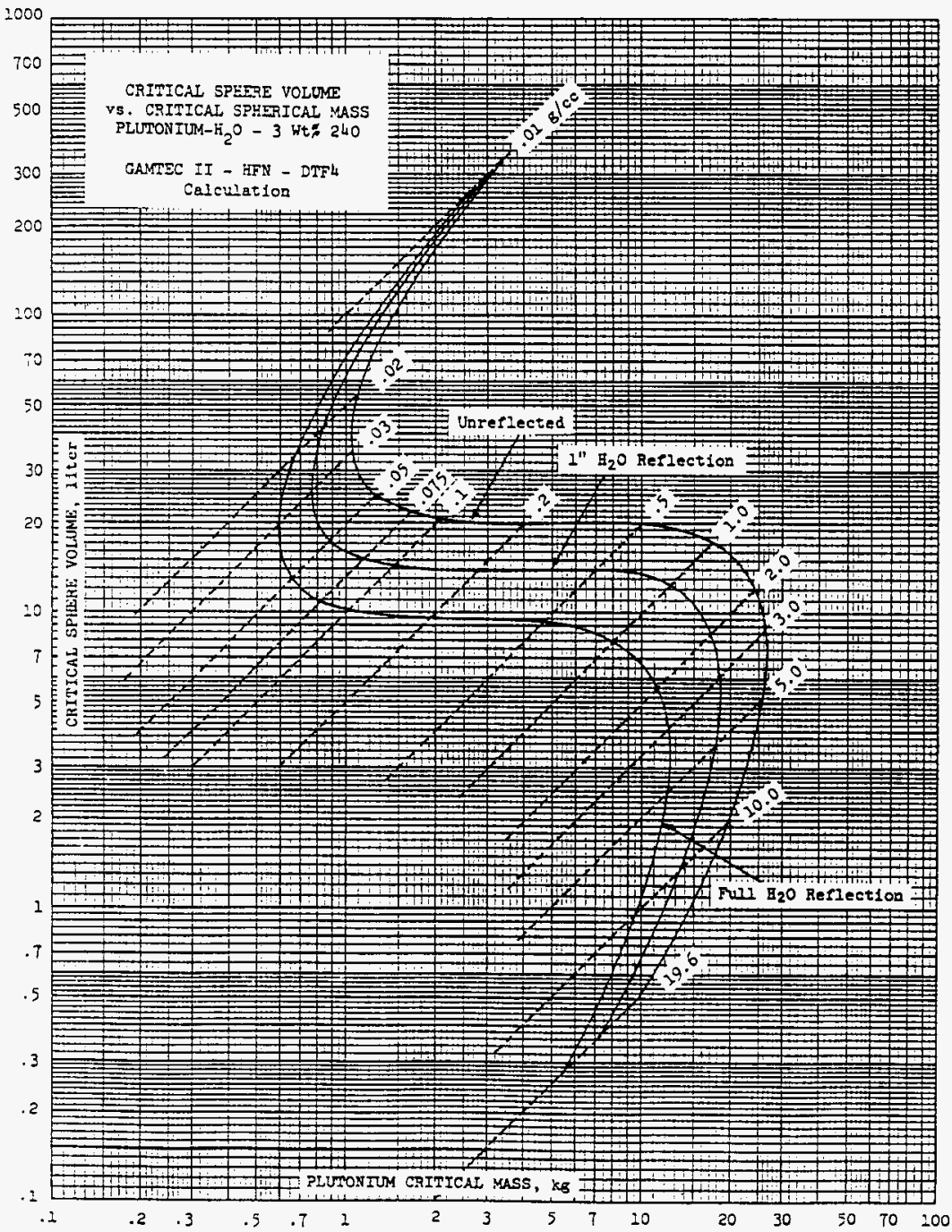




\section{DISTRIBUTION SHEET}

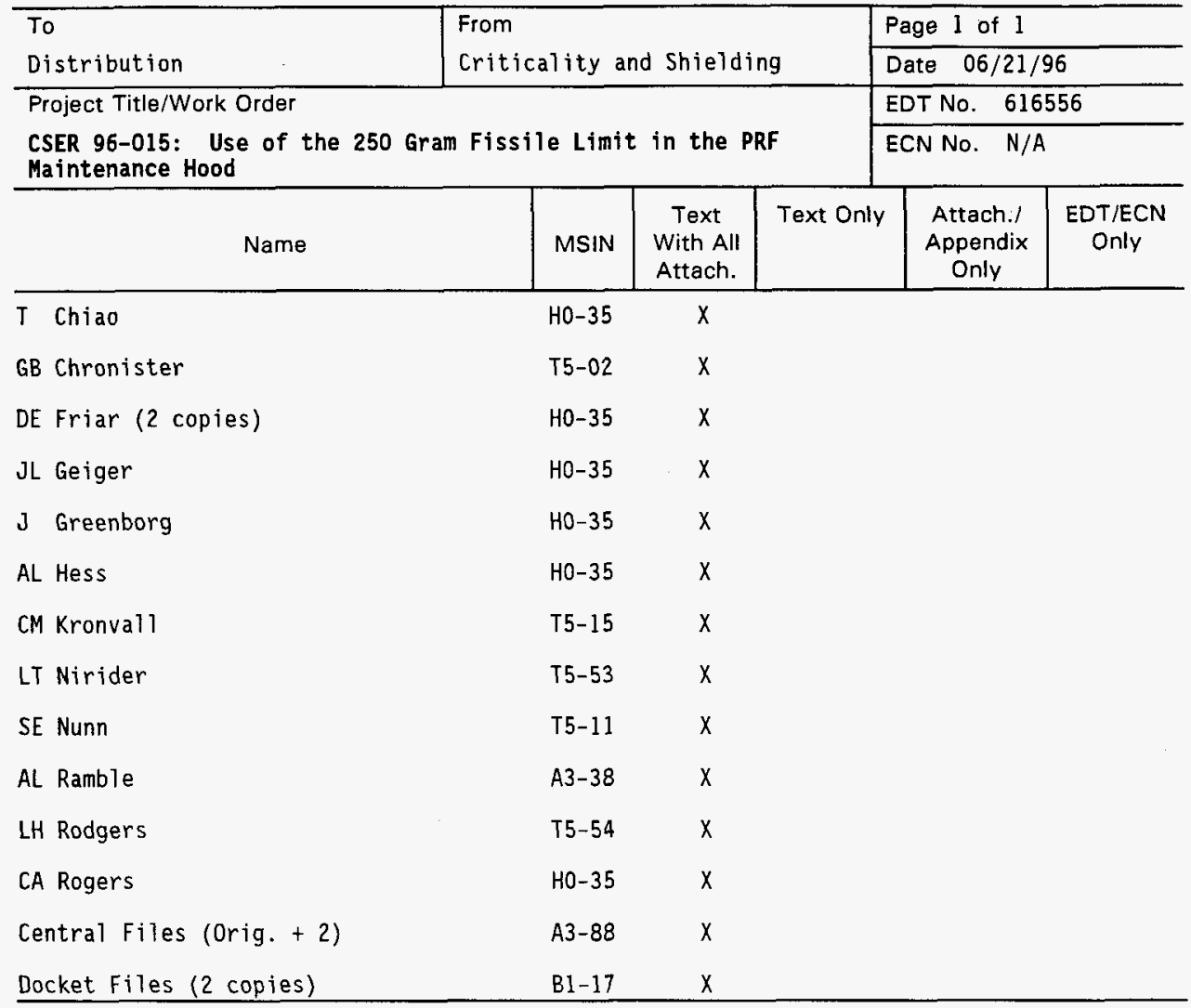

